\title{
SISTEM E-LEARNING DALAM PEMBELAJARAN $i B T$ TOEFL (INTERNET BASE TEST OF ENGLISH AS A FOREIGN LANGUAGE) MENGGUNAKAN MEDIA VOIP (VOICE OVER INTERNET PROTOCOL)
}

\author{
Muchammad Husni*, Endang Susilowati ${ }^{\dagger}$
}

\begin{abstract}
Abstrak
Dengan semakin berkembangnya komunikasi internasional saat ini, seseorang dituntut untuk memiliki kemampuan berkomunikasi dalam bahasa global, diantaranya adalah bahasa Inggris. Salah satu alat untuk mengukur kemampuan berbahasa Inggris adalah dengan menggunakan TOEFL (Test of English as a Foreign Languge). iBT TOEFL ( Internet Base Test TOEFL) mengukur kemampuan pembelajar untuk memahami, menggunakan dan mengerti bahasa Inggris ditingkat Universitas, disamping itu, test ini juga mengevaluasi seberapa baik pembelajar menggabungkan keterampilan mendengarkan/menyimak (listening), berbicara (speaking), membaca (reading), dan menulis (writing) dalam bahasa Inggris. Penelitian ini akan mengembangkan Sistem E-learning untuk pembelajaran (Pelatihan dan Tes) TOEFL menggunakan jaringan intranet yang dapat digunakan untuk mengukur kemampuan TOEFL pembelajar dengan memberikan hasil keluaran berupa kelemahan seseorang dalam menjawab soal-soal tes. iBT TOEFL terdiri atas 4 (empat) bagian tes yaitu Listening, Writting, Reading dan Speaking. Sistem E-learning ini akan disertai dengan soal-soal latihan yang disesuaikan dengan kelemahan kemampuan TOEFL dari pembelajar/pengguna. Dengan demikian diharapkan Sistem E-learning ini dapat membantu pembelajar untuk meningkatkan kemampuan TOEFL sehingga target nilai TOEFL yang diinginkan dapat tercapai. Dalam sistem E-learning ini juga disediakan jalur komunikasi suara antara pembelajar/pengguna dengan penilai (assessor) yang dikembangkan dengan teknologi VoIP untuk membantu pengguna dalam melatih teknik berbicara (speaking) dalam bahasa Inggris.
\end{abstract}

Kata kunci: sistem e-learning, pembelajaran iBT TOEFL (Internet Base Test of English as a Foreign Language ), VoIP ( Voice over Internet Protocol )

Kemampuan berbahasa Inggris mempunyai arti yang sangat penting, karena sangat diperhitungkan dalam dunia pendidikan maupun dunia kerja, sehingga banyak orang yang memperdalam kemampuan berbahasa Inggris. Salah satu ukuran dari kemampuan berbahasa Inggris seseorang dapat dilihat dari hasil nilai TOEFL yang diperoleh. Besarnya nilai test TOEFL dengan standar yang telah ditentukan dapat digunakan untuk berbagai syarat seleksi, antara lain beasiswa, studi lanjut, baik di dalam negeri maupun di luar negeri, rekrutment pegawai maupun sebagai salah satu syarat kelulusan dari suatu Perguruan Tinggi.

\footnotetext{
* Dosen Teknik Informatika FTIf ITS

${ }^{\dagger}$ Dosen UPM Soshum ITS 
Pembelajar yang menginginkan untuk mendapatkan nilai TOEFL tertentu, seringkali harus melakukan test TOEFL lebih dari satu kali. Disisi lain, ia harus mengikuti pelatihan atau kursus khusus sebelum mengikuti test. Pelatihan ini biasanya hanya digunakan untuk satu kali test, sehingga untuk memenuhi target yang diinginkan, perlu melakukan pelatihan berulang-ulang, dengan demikian menjadi tidak efisien.

Penelitian ini akan membuat suatu sistem yang bisa membantu pembelajar untuk melakukan test TOEFL sekaligus latihan-latihan soal TOEFL secara on line dilingkungan intranet sehingga diharapkan dapat mencapai score TOEFL yang diharapkan. Sistem ini akan memberikan materi pelatihan secara on-line yang disertai dengan pembahasan soal. Sebelum melakukan pelatihan, pengguna harus melakukan test awal untuk mendiagnosa kemampuan TOEFL pengguna. Dari hasil diagnosa ini akan diketahui kelemahan TOEFL pengguna. Sistem juga akan memberikan informasi nilai yang didapat pada setiap latihan. Soal latihan tersebut terdiri atas listening comprehension, structure and written, reading comprehension, dan speaking sesuai dengan standart soal ujian TOEFL.

Artikel ini mensarikan hasil penelitian dengan rumusan dan batasan masalah sebagai berikut:

1. Bagaimana membuat sistem untuk menghitung nilai TOEFL pengguna, dan mendapatkan parameter untuk mengetahui kelemahan TOEFL pembelajar/pengguna.

2. Bagaimana membuat sistem yang dapat memberikan soal pelatihan TOEFL kepada pengguna sesuai dengan kelemahan TOEFL pengguna.

3. Bagaimana membuat sistem yang dapat diakses oleh pengguna secara mudah dari mana saja asalkan masih dalam lingkup jaringan intranet.

4. Sistem hanya mengidentifikasi kelemahan kemampuan TOEFL pengguna berdasarkan per bagian dari TOEFL, bukan berdasarkan jenis pertanyaan pada setiap bagian.

Serta tujuan penelitian ini adalah merancang dan membuat sistem untuk pelatihan dan test TOEFL berbasis intranet, dan manfaatnya adalah untuk membantu sistem pembelajaran dan pelatihan tes TOEFL berbasis intranet. Sistem yang dibuat 
ini diharapkan dapat mengetahui kelemahan kemampuan TOEFL pengguna. Disamping itu sistem juga dapat memberikan materi pelatihan atau soal yang sesuai dengan kelemahan TOEFL pengguna.

\section{E-Learning}

Istilah e-Learning menurut Darin E. Hartley adalah: "E-Learning merupakan suatu jenis belajar mengajar yang memungkinkan tersampaikannya bahan ajar ke pembelajar dengan menggunakan media Internet, Intranet atau media jaringan komputer lain."

LearnFrame.Com dalam Glossary of e-Learning Terms menyatakan suatu definisi yang lebih luas, dimana e-Learning adalah sistem pendidikan yang menggunakan aplikasi elektronik untuk mendukung belajar mengajar dengan media Internet, jaringan komputer, maupun komputer standalone.

Dari definisi-definisi tersebut, dapat disimpulkan bahwa e-learning merupakan:

1. Metode belajar mengajar baru yang menggunakan media jaringan komputer dan Internet.

2. Tersampaikannya bahan ajar (konten) melalui media elektronik. Otomatis bentuk bahan ajar juga dalam bentuk elektronik (digital).

3. Adanya sistem dan aplikasi elektronik yang mendukung proses belajar mengajar.

\section{Dokeos}

Dokeos adalah e-learning tools untuk aplikasi berbasis web yang dikembangkan oleh GNU GPL dan didukung oleh dunia internasional. Dokeos ini merupakan sistem yang bagus untuk pembelajaran, fleksibel dan mudah digunakan. Dokeos ditulis dalam bahasa PHP dan menggunakan database MySQL.

Berikut ini adalah fitur-fitur yang terdapat pada Dokeos:

1. Agenda/kalender

2. Pengumuman: info penting yang juga mencakup fungsionalitas mail service.

3. Deskripsi arahan: penjelasan objektif, metodologi, materi kursus, metode taksiran untuk pembelajar.

4. Dokumen: manajemen file untuk menyimpan berbagai dokumen. 
5. Learning path: menetapkan bagaimana pembelajar melakukan browsing. Menjelaskan kepada pembelajar langkah mana yang harus diambil. Dengan fitur ini dosen/pengajar bisa mengatur prasyarat, misalnya: situs tidak dapat dikunjungi sebelum test diselesaikan.

6. Link: link ke situs lain.

7. Forum: diskusi asynchronous.

8. Drop box: pembelajar dapat mengumpulkan tugas ke dosen/pengajar

9. Group: mengelompokkan beberapa pembelajar/user menjadi satu (untuk tugas spesifik).

10. Modul untuk chat : diskusi instant.

11. Publikasi: pembelajar dapat membagi tugas mereka dengan pembelajar yang lain

12. Tracking: informasi tentang siapa yang telah mengerjakan dan kapan.

\section{VolP}

Voice over Internet Protocol (VoIP) adalah teknologi yang memungkinkan kemampuan melakukan percakapan telepon dengan menggunakan jalur komunikasi data pada suatu jaringan (networking). Sehingga teknologi ini memungkinkan komunikasi suara menggunakan jaringan berbasis IP (internet protocol) untuk dijalankan diatas infrastruktur jaringan packet network. Jaringan yang digunakan bisa berupa internet atau intranet. Teknologi ini bekerja dengan jalan merubah suara menjadi format digital tertentu yang dapat dikirimkan melalui jaringan IP. VoIP lebih mengacu pada layanan komunikasi suara (voice), faksimili, dan voice messaging applications. Teknologi ini pada dasarnya mengkonversi sinyal analog (suara) ke format digital dan kemudian dimampatkan atau ditranslasikan ke dalam paket-paket IP yang kemudian ditransmisikan melalui jaringan Internet. Topologi Jaringan VoIP dapat dilihat pada Gambar 2.1. 


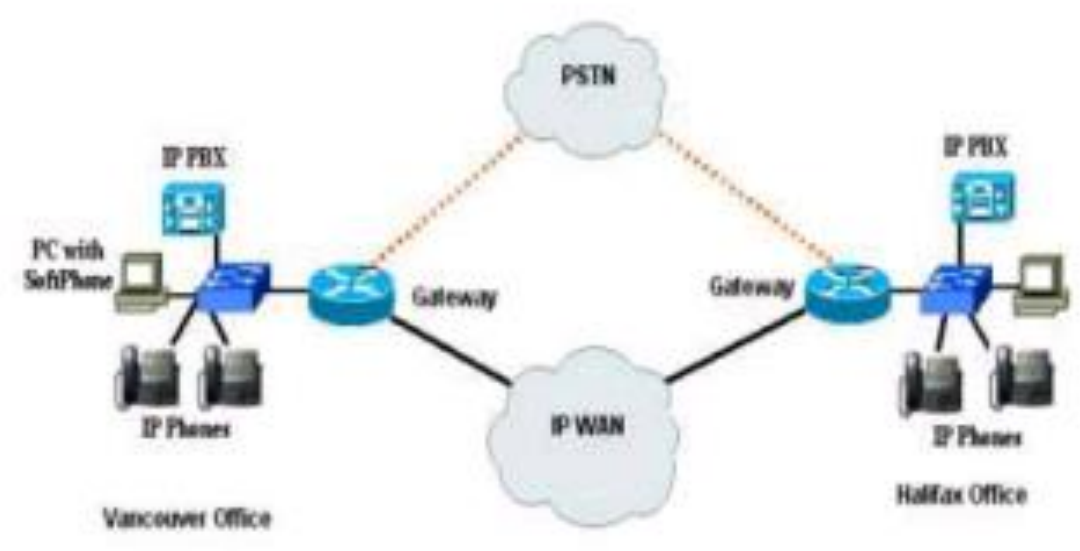

Gambar 2.1 Topologi Jaringan VoIP

\section{iBT TOEFL}

iBT TOEFL (Test Of English As A Foreign Language) merupakan test berbasis jaringan internet yang digunakan untuk mengukur kemampuan berbahasa Inggris pembelajar. Setiap pembelajar yang mengikuti test TOEFL akan mendapatkan nilai yang menggambarkan kemampuan bahasa Inggrisnya. iBT TOEFL terdiri atas 4 (empat) bagian yaitu Listening, Writing, Reading dan Speaking.

Pada sesi Listening peserta tes akan mendengarkan soal melalui audio berupa percakapan antara dua orang dan sebuah tema yang akan dibacakan oleh speakers. Untuk setiap percakapan dan tema yang dibacakan terdapat beberapa katagori pertanyaan yang harus dijawab. Sesi Listening ini akan mengukur kemampuan pembelajar/pengguna dalam mendengarkan dan kemudian menangkap makna suatu percakapan atau mendengarkan suatu tema yang dibacakan dalam bahasa Inggris.

Pada bagian Writing pengguna akan mendapatkan pertanyaan yang terdiri atas dua bagian. Bagian pertama melengkapi suatu kalimat dengan kata yang benar berdasarkan struktur dan aturan penulisan (grammar) dalam bahasa Inggris. Sedangkan bagian kedua mencari kata yang salah yang tidak sesuai dengan struktur dan aturan penulisan yang terdapat dalam satu kalimat. Bagian ini dimaksudkan untuk mengukur kemampuan pembelajar dalam penulisan kalimat berbahasa Inggris yang sesuai dengan struktur. 
Bagian Reading menyediakan suatu bacaan dengan topik yang beragam disertai pertanyaan yang sesuai dengan bacaan tersebut. Bagian ini dimaksudkan untuk dapat mengukur kemampuan pembelajar untuk mengerti, menterjemahkan maksud dari suatu bacaan dan memberikan analisis terhadap suatu bacaan yang ditulis dengan bahasa Inggris.

Sesi speaking ini terdiri dari beberapa bagian, namun umumnya, setiap bagian saling independen. Topik paparannya terfokus pada opini dan pengalaman pribadi pembelajar/pengguna. Tugas pengguna di sesi ini khususnya pada ketrampilan memahami sesi reading dan listening. Semua proses akan direkam melalui mikrofon dan dikirim melalui jaringan intranet.

\section{Studi Hasil Penelitian Sebelumnya}

Pada sistem pelatihan tes TOEFL umumnya hanya terjadi searah dari sisi pembelajar tanpa ada bimbingan dari pengajar secara interaktif. Selain itu, sistem hanya memberikan hasil akhir berupa nilai TOEFL yang diperoleh seorang pembelajar tanpa memberitahukan dari aspek mana pembelajar tersebut mengalami kekurangan dalam pengerjaan.

Penelitian ini diharapkan dapat meningkatkan interaktifitas antara para pembelajar dan pengajar, serta dapat meningkatkan kemampuan pembelajar dalam mengerjakan soal-soal tes TOEFL.

Penelitian ini diawali dengan studi literatur, analisis dan desain, implementasi, serta diakhir dengan uji coba. Secara lebih detil, penelitian ini dirancang dengan urutan sebagai berikut:

\section{Studi Pustaka}

Dalam penelitian ini terdapat tiga bagian utama yaitu iBT TOEFL, sistem manajemen pembelajaran, dan pengiriman suara melalui jaringan intranet. Studi literatur akan mengkaji berbagai referensi tentang tiga topik tersebut, sehingga bisa ditemukan kekurangan dan kelebihan metode yang sudah diteliti sebelumnya dari masing-masing topik. 


\section{Analisis dan Desain}

Tahap awal analisis dan desain adalah merumuskan kontribusi utama penelitian ini. Dari test awal akan diketahui nilai iBT TOEFL pengguna. Informasi ini akan diproses lebih lanjut sehingga diketahui kelemahan kemampuan iBT TOEFL pengguna. Identifikasi kelemahan ini didapat dari jumlah jawaban benar terkecil dari ke empat sesi test iBT TOEFL. Sistem kemudian akan memberikan latihan soal yang sesuai.

\section{Implementasi}

Dalam tahap ini, diimplementasikan rancangan yang telah dibuat pada proses sebelumnya. Bahasa pemrograman yang digunakan adalah bahasa $\mathrm{C}$, shell script, dan PHP sebagai antarmuka berbasis web. Implementasi dilakukan pada server fisik dan tidak menggunakan simulasi. Adapaun spesifikasi servernya adalah sebagai berikut:

- Prosesor Intel Core i3 $4 \mathrm{GHz}$

- Memori $4 \mathrm{GHz}$

- Hard disk $250 \mathrm{~GB}$

- Sistem operasi berbasis Linux

- Modul Dokeos

- Modul Asterisk

\section{Uji coba dan Evaluasi}

Untuk menguji apakah kontribusi yang diajukan bisa berjalan dengan baik, perlu dilakukan uji coba. Uji coba dilakukan pada server yang telah dikonfigurasi dan ditambahkan modul yang diajukan. Skenario uji coba dilakukan dengan sejumlah pengguna yang bertindak sebagai peserta test. Hasil uji coba akan dievaluasi.

\section{Langkah-langkah Penelitian}

Langkah-langkah penelitian secara umum disajikan dalam Gambar 3.1. Langkah pertama adalah mempersiapkan server beserta modul pendukungnya. 


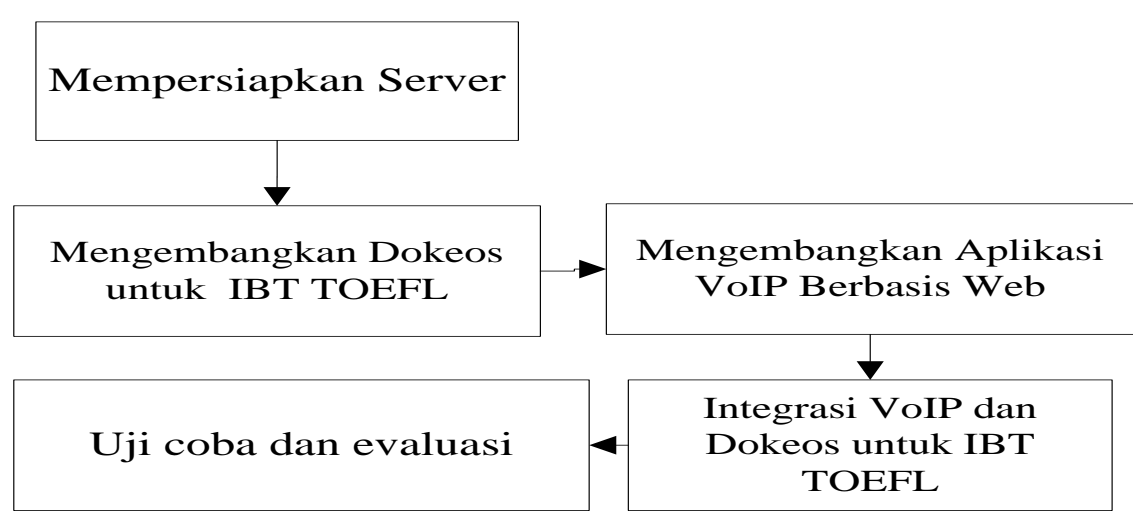

Gambar 3.1 Langkah-Langkah Penelitian

\section{Mempersiapkan Server}

Server yang digunakan menyediakan layanan web. Apache dipilih sebagai server web karena sudah banyak digunakan dan terbukti kehandalannya. Setelah itu, dipasang dan dikonfigurasi Dokeos sebagai sistem manajemen pembelajaran dan Asterisk, sebagai media VoIP. Disamping itu di lengkapi juga dengan perangkat lunak pendukung lainnya.

\section{Mengembangkan Dokeos untuk IBT TOEFL}

Diagram blok di bawah menunjukkan metode yang digunakan untuk mengembangkan Dokeos untuk iBT TOEFL

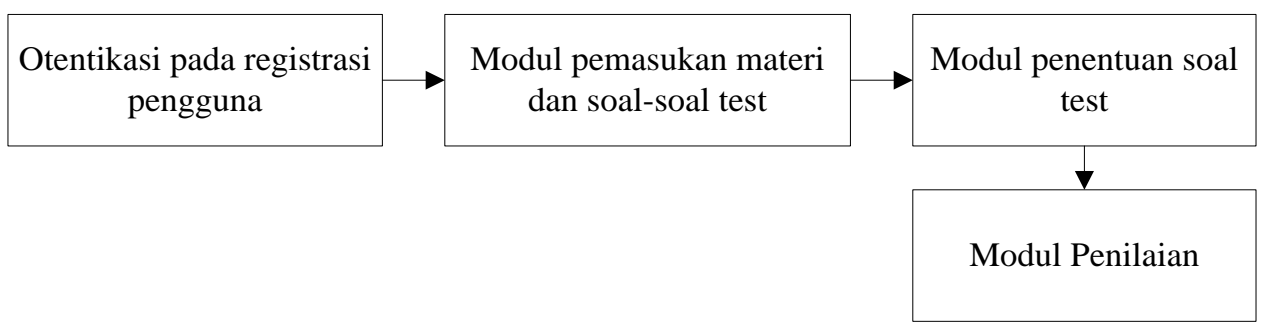

Gambar 3.2 Diagram blok Pengembangan Dokeos Untuk iBT TOEFL

Proses penanganan registrasi pengguna pada aplikasi web di halaman utama dilengkapi dengan pemberian nomor identitas pengguna dan pengisian biodata. Nomor ini yang dilengkapi dengan password akan digunakan untuk melakukan login ke sistem. Modul pemasukan materi dan soal-soal test berfungsi untuk memasukkan materi dan soal-soal test baik berbentuk teks maupun multimedia. Pada modul penentuan soal test, sistem akan "melihat" dibagian mana kelemahan pengguna. Informasi ini akan digunakan oleh sistem untuk memilihkan soal yang sesuai dengan kondisi tersebut. Sedang modul penilaian akan menghitung berapa 
nilai total dari hasil test yang telah dilakukan. Penilaian ini akan dilaporkan dalam dua versi, yakni standar iBT TOEFL dan TOEFL.

\section{Mengembangkan Aplikasi VolP Berbasis Web}

Diagram blok di bawah menunjukkan metode yang digunakan untuk mengembangkan Asterisk untuk IBT TOEFL

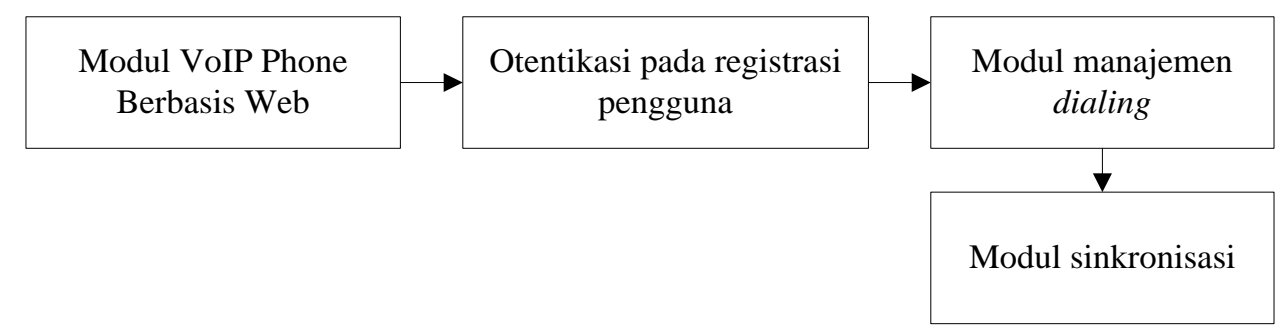

Gambar 3.3 Diagram blok Pengembangan Asterisk Untuk iBT TOEFL

Saat ini VoIP phone yang banyak beredar adalah berbasis desktop, sedangkan pada penelitian ini system akan berbasis web. Oleh karena itu, tahap awal adalah mengembangkan VoIP phone yang berbasis web. Integrasi awal harus dilakukan yaitu dengan model single identity, dimana saat seorang pengguna masuk ke system, maka system e-learning dan VoIP harus mengenalinya. Pada modul dialing ini, akan dikembangkan aktifitas dial untuk peer to peer connection dan audio conference. Sedang modul sinkronisasi akan memberikan petunjuk atau tanda kepada para pengguna, siapa pengguna yang saat ini sedang melakukan komunikasi dengan pengajar.

\section{Integrasi VolP dan Dokeos untuk iBT TOEFL}

Pada fase ini, kegiatan terfokus pada implementasi, sinkronisasi, dan pengaturan beberapa modul yang telah dibuat sebelumnya. Adapun model dari sistem secara keseluruhan bisa ditunjukkan pada Gambar 3.4. 


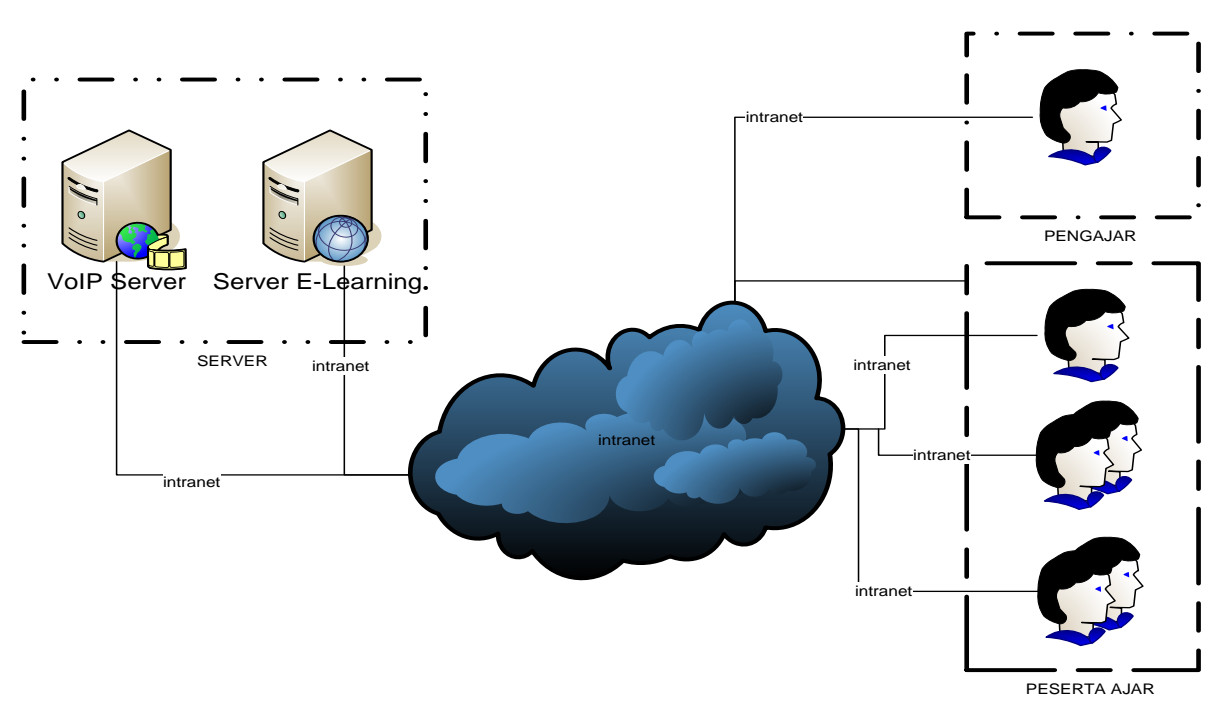

Gambar 3.4 Arsitektur Sistem E-Learning untuk iBT TOEFL menggunakan VoIP

\section{Uji Coba dan Evaluasi}

Pada tahap ini akan dilakukan uji coba terhadap sistem yang telah dirancang pada obyek penelitian dan melakukan analisis dan evaluasi terhadap hasil yang didapat.

Analisis capaian luaran terhadap target luaran selama waktu penelitian yang sudah berjalan adalah sebagai berikut:

\section{Integrasi Sistem E-learning Dokeos dan Aplikasi VolP Berbasis Web Rancangan Sistem}

Sistem yang dibuat ini merupakan integrasi sistem manajemen pembelajaran Dokeos dengan VoIP web client. Dengan adanya integrasi tersebut, user yang terdaftar pada Dokeos secara otomatis juga terdaftar pada VoIP server sehingga dapat melakukan panggilan atau menerima panggilan melalui layanan VoIP. Protokol VoIP yang digunakan dalam implementasi ini adalah protokol SIP dengan menggunakan codec G.711. Untuk menggunakan aplikasi ini dengan baik pada klien, maka dibutuhkan :

- Koneksi jaringan dengan server sistem ini, baik itu intranet maupun internet.

- Browser yang memiliki plugin flash player.

Untuk instalasi server diperlukan spesifikasi komputer dengan kebutuhan:

- Koneksi dengan jaringan. 
- Web server PHP untuk menjalankan web, seperti Apache, yang mendukung PHP 5.

- Database server MySQL untuk keperluan penyimpanan data.

- Antarmuka administrator untuk mengakses database server, seperti phpmyadmin.

- Red5 RTMP server untuk proses streaming audio yang digunakan oleh VoIP web client.

- Asterisk

Dalam sistem ini terdapat dua sistem yang menggunakan port berbeda dalam menjalankan fungsinya. Oleh karena hal tersebut, perlu dibuat rancangan sistem yang baik untuk mengintegrasikannya. Proses perancangan sistem ini meliputi tahap pembuatan arsitektur sistem serta jalannya algoritma yang digambarkan dalam diagram alir.

\section{Arsitektur Sistem}

Rancangan arsitektur sistem secara keseluruhan seperti terlihat pada Gambar 4.1. Web browser akan menampilkan halaman dari sistem manajemen pembelajaran Dokeos. Untuk menggunakan fitur VoIP client, sistem menggunakan web servis pada Dokeos dengan pertukaran data berformat JSON.

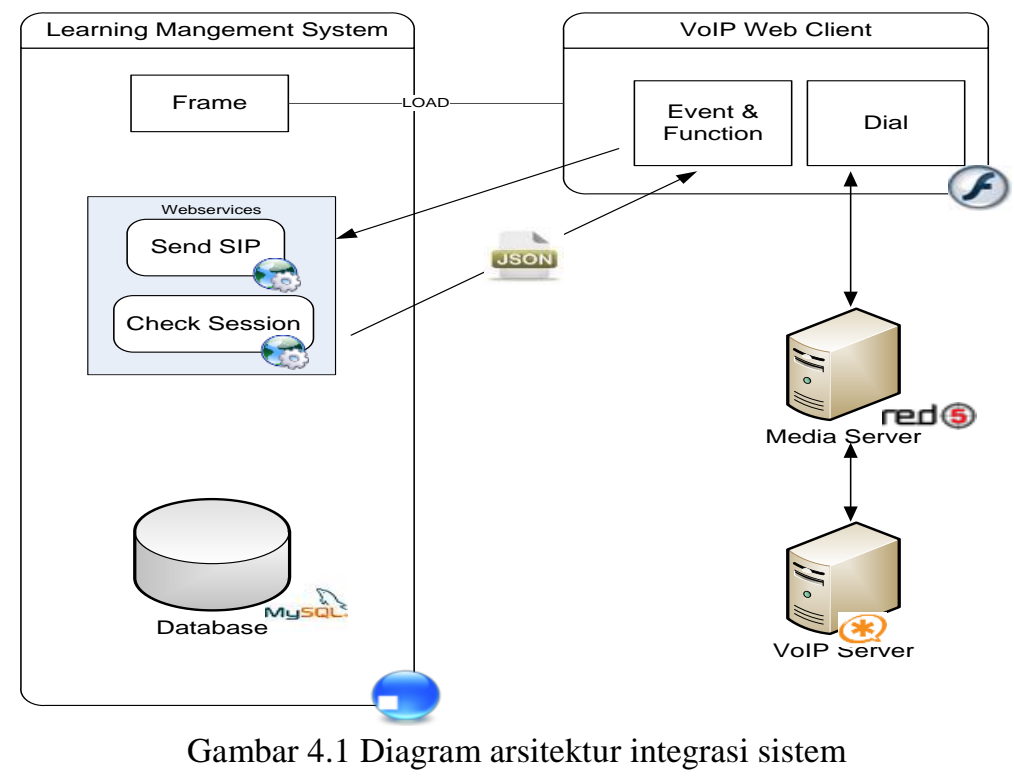




\section{Algoritma dan Flowchart}

Untuk implementasi beberapa fungsi dalam sistem terintegrasi dibutuhkan algoritma yang menjelaskan bagaimana sebuah proses diimplementasikan ke dalam fungsi. Algoritma tersebut kemudian digambarkan dengan flowchart, seperti: Agoritma dan Flowchart Register User dan Algoritma Flowchart Course.

\section{Perancangan Diagram Use Case}

Fungsionalitas sistem beserta aktor yang terlibat digambarkan dalam diagram use case sebagi berikut (Gambar 4.2):

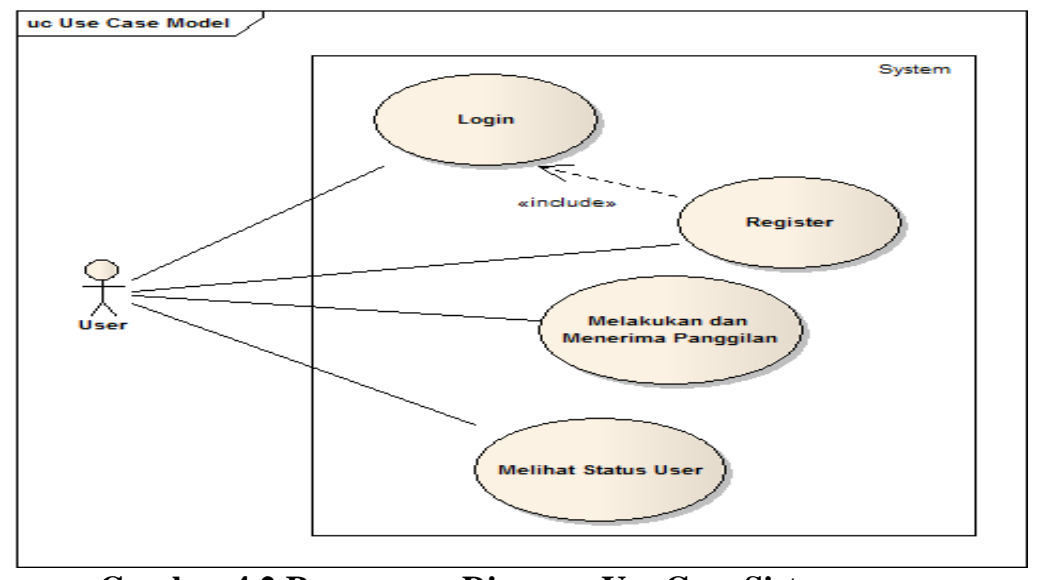

Gambar 4.2 Rancangan Diagram Use Case Sistem

\section{Flowchart Aplikasi}

Alur setiap proses yang terdapat pada aplikasi digambarkan pada diagram flowchart, untuk memudahkan pemahaman secara garis besar proses yang ada pada sistem, yaitu : Flowchart Proses Register User, Flowchart Proses Login User, serta Flowchart Proses Call and Answer.

\section{Hasil Implementasi Sistem E-Learning untuk IBT TOEFL}

Pada System Pembelajaran Untuk Pelatihan dan Tes TOEFL Menggunakan VoIP ini digunakan teknologi LMS (Learning Management System) Dokeos dengan melakukan modifikasi di dalamnya sehingga LMS tersebut dapat digunakan dalam manajemen tes dan pelatihan TOEFL. Adapun desain sistem dari aplikasi ini adalah seperti pada Gambar 4.3. 


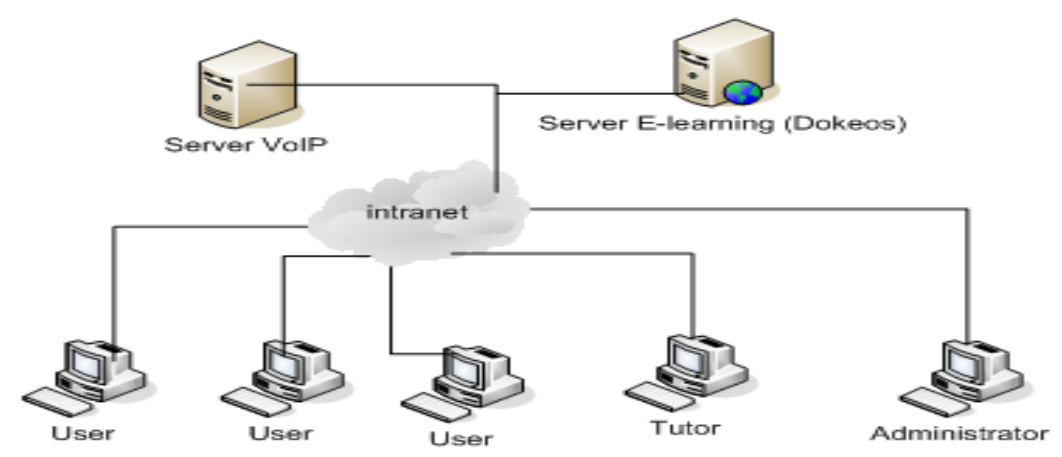

Gambar 4.3 rsitektur Sistem E-Learning untuk iBT TOEFL menggunakan VoIP

Dalam sistem ini client VoIP yang digunakan terpisah dari web, peneliti akan menggunakan desktop client VoIP X-lite yang digunakan pada apabila pembelajar (Learner) ingin berdiskusi atau bertanya sesuatu kepada administrator.

Dalam aplikasi Sistem Pembelajaran Untuk Pelatihan dan Tes TOEFL Menggunakan VoIP ini melibatkan dua macam aktor, yaitu antarmuka administrator dan learner. Hubungan antar aktor dan system dapat digambarkan dalam diagram usecase seperti pada Gambar 4.4.

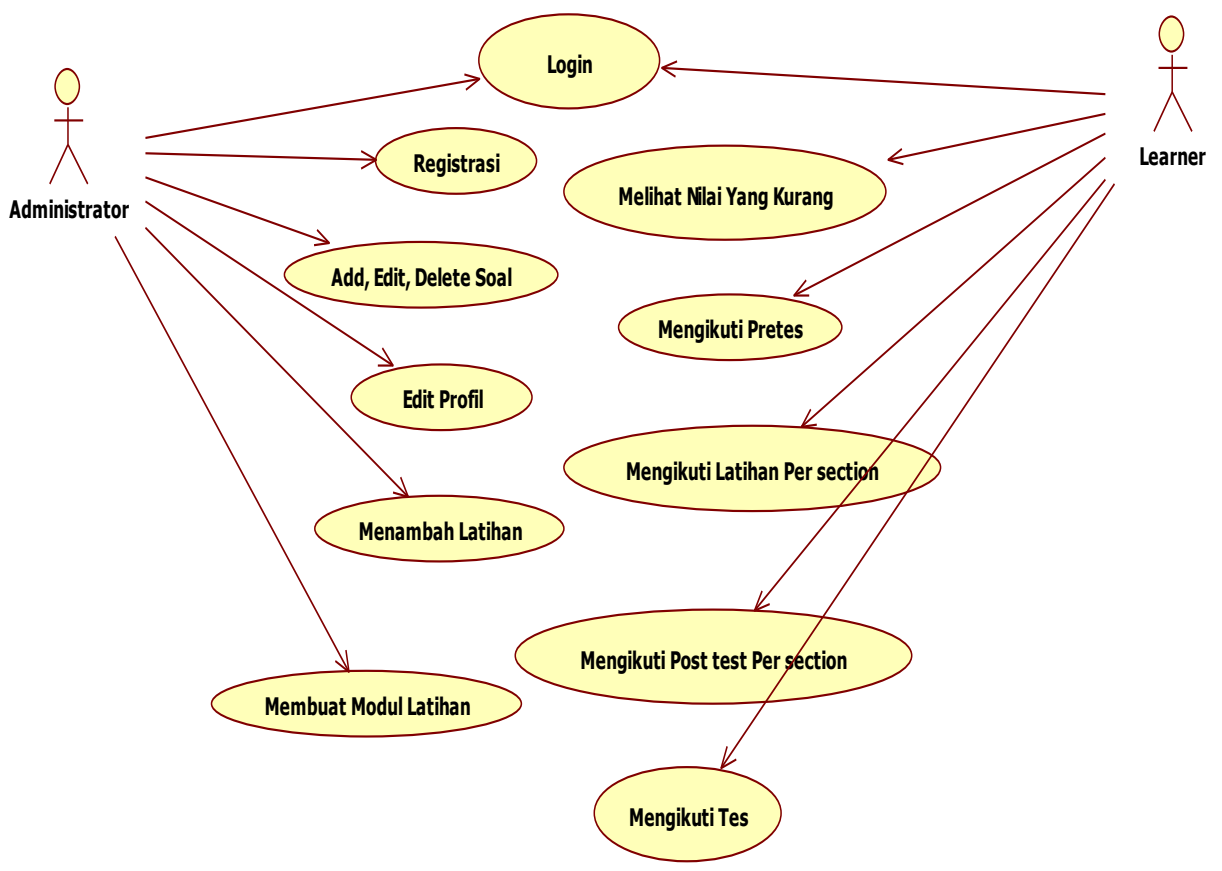

Gambar 4.4 Usecase Sistem E-Learning untuk iBT TOEFL menggunakan VoIP Adapun fitur- fitur dari aplikasi ini antara lain:

1. Login 
Fitur ini berada pada Administrator side dan Learner side, merupakan fitur untuk masuk ke dalam sistem.

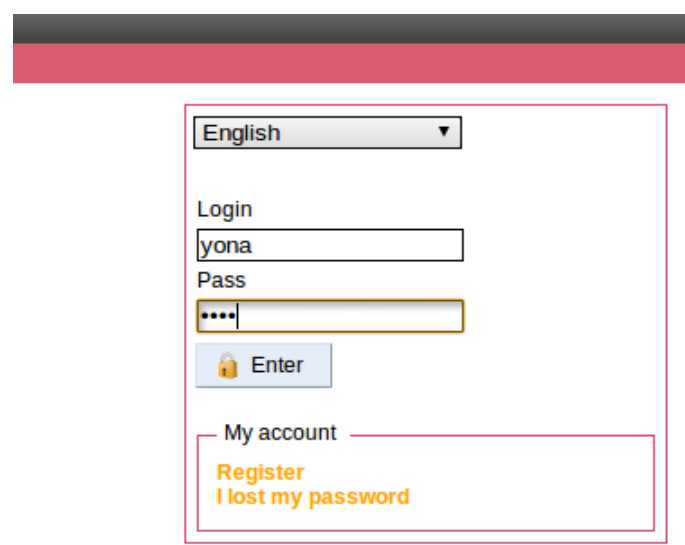

Gambar 4.5 Tampilan Login

1. Register

Berada pada Learner side, untuk mendaftar ke dalam sistem.

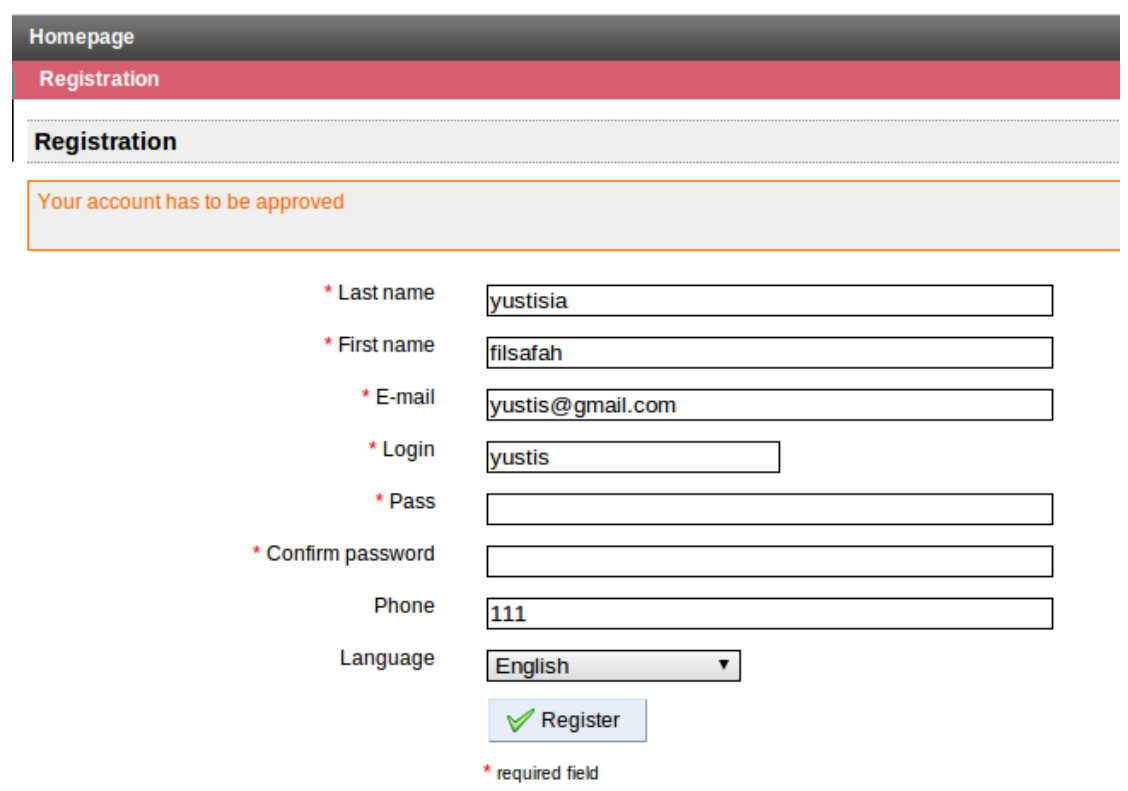

Gambar 4.6 Tampilan untuk Pendaftaran User Baru

2. Menambah soal

Berada pada administrator side, berguna untuk menambah soal ke dalam database. 


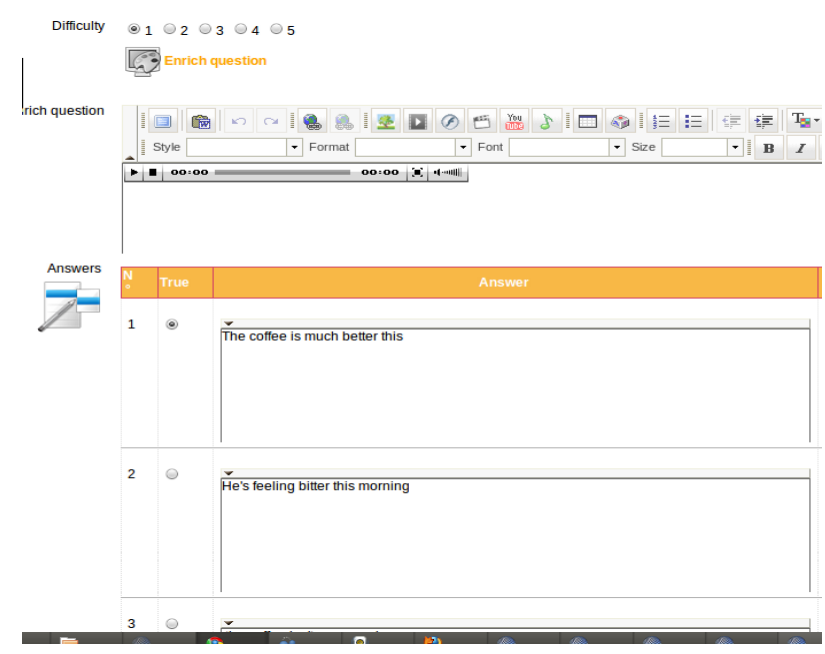

Gambar 4.7 Tampilan untuk Menambah Soal

3. Manage User

Berada pada sisi administrator, berguna untuk menambah, mengubah atau menghapus user.

\begin{tabular}{|c|c|c|c|c|c|c|c|c|}
\hline Homep & of Traiking & Profile & & & & & & \\
\hline Admin & seration > Users & & & & & & & \\
\hline$\square$ & 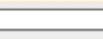 & Q Search & Advanced search & & & & & \\
\hline & & & & & $1.8 / 8$ & & & \\
\hline & I code & I Lastname & I firstnene & Logh & Emant & Pronter & Acthe & Eath \\
\hline$\square$ & $\cdot$ & a & a & a & ateyahoocom & Learner & 0 & 典 $900 x$ \\
\hline a & $\cdot$ & d & d & d & defymalicom & Leaner & $\theta$ & 罡 $980 x$ \\
\hline$a$ & & prima & prima & perma & primefogmallcom & Learner & 0 & 異 $900 x$ \\
\hline a & ADMMN & Pramastur & sytta & admin & syltheprimastutiogmalicom & Trainer & - & 貫 9 $80 x$ \\
\hline e & $\cdot$ & $\tan$ & wata & wata & tataggmailcom & Leamer & 0 & 零 (90 8 \\
\hline a & $\cdot$ & les & tos & es & tosegmall.com & Leamer & 0 & 買 $900 \times$ \\
\hline$a$ & - & yona & yona & yona & yona fgrailicom & Leamer & 0 & 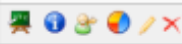 \\
\hline$\square$ & - & yustsia & Alsatah & yustis & yustisegmailicom & Leaner & $\ominus$ & 誉 $90 \%$ \\
\hline Select: & 1. Unselectas & Remove from portal - & $\checkmark$ valioalte & & & & & \\
\hline
\end{tabular}

Gambar 4.8 Tampilan untuk Manage User

4. Mengikuti Tes

Berada pada Learner Side, untuk mengikuti tes. 

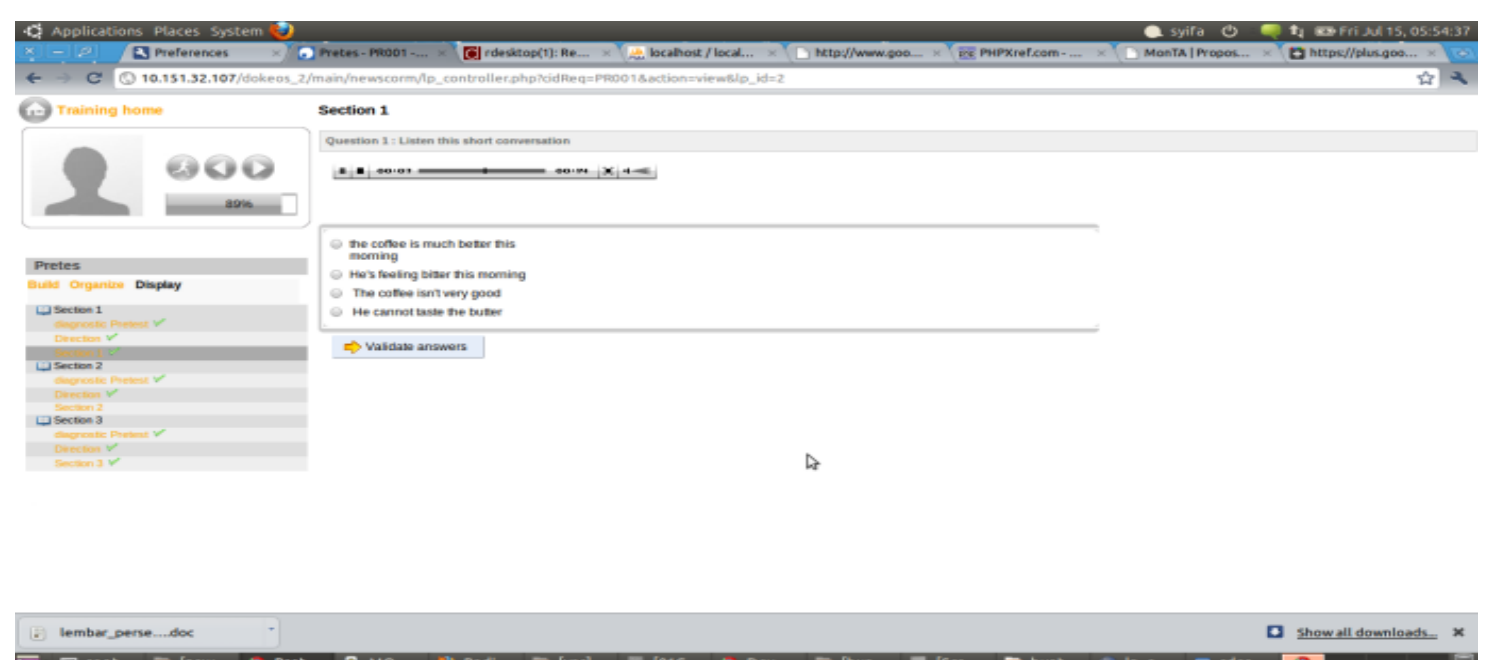

Gambar 4.9 Tampilan Ketika Mengikuti Tes TOEFL

5. Melakukan panggilan via VoIP ke Administrator.
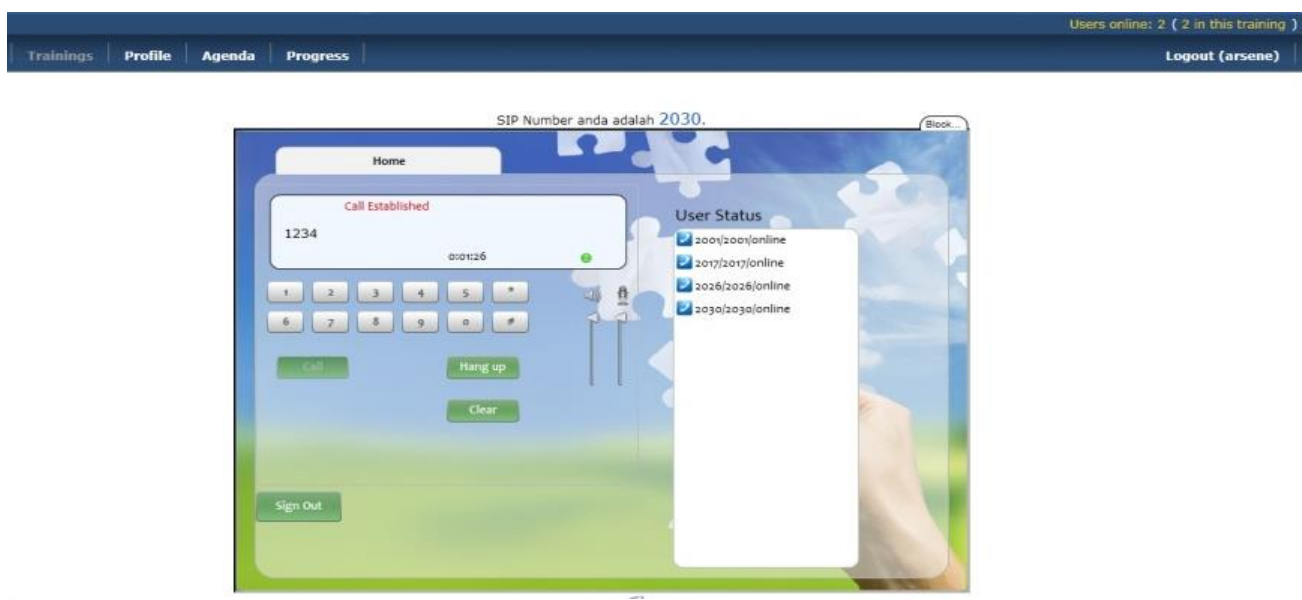

Gambar 4.10 Tampilan Ketika Melakukan Komunikasi via VoIP

\section{Kesimpulan dan Saran}

Dari hasil penelitian yang telah dilakukan dan analisa terhadap hasil ujicoba dari beberapa implementasi yang sudah dilakukan dapat ditarik beberapa kesimpulan sebagai berikut:

1. Aplikasi Sistem pembelajaran online untuk test dan pelatihan TOEFL ini dapat diimplementasikan dengan menggunakan LMS (Learning Management System) Dokeos dan VoIP

2. Sistem pembelajaran online untuk test dan pelatihan TOEFL ini dapat digunakan untuk mengetahui nilai kelemahan TOEFL pengguna 
3. Sistem manajemen pembelajaran dokeos dapat menggunakan fitur sistem VoIP berbasis SIP dengan memanfaatkan implementasi web service.

4. Aplikasi VoIP berbasis web dapat digunakan untuk komunikasi VoIP, registrasi user SIP, dan melihat user online.

Saran yang dapat dilakukan untuk pengembangan sistem pada penelitian berikutnya adalah sebagai beriku:

1. Antarmuka sistem dapat diperbaiki lagi agar semakin menarik dan interatif. Selain itu, dengan tampilan yang menarik akan memperbesar minat user untuk memakai aplikasi ini

2. Pada bagian administrasi semakin dipermudah, agar dalam pembuatan isi dan materi pembelajaran semakin mudah dan cepat.

3. Peningkatan kualitas suara pada komunikasi VoIP dapat dilakukan dengan pengimplementasian codec yang lebih berkualitas.

4. Melakukan perbaikan terhadap sistem pembelajaran test TOEFL iBT, terutama mengenai alur dan feedback dari sistem mengenai analisa kelemahan berdasarkan hasil tes TOEFL dari pengguna sistem.

\section{Daftar Pustaka}

Darin E. Hartley, Selling E-Learning (The Astd E-Learning Series), 2001

Glossary of e-Learning Terms, http:// www.learnframe.com/

Stephen Downes, E-Learning

URL:http://www.elearnmag.org/subpage.cfm?section=articles\&article=29-1 >

E-Learning Management System <URL: http://www.dokeos.com >

Douglas Pierce, Cracking the TOEFL iBT,

Skandarsyah, M “Dasar-dasar Jaringan VoIP”, IlmuKomputer, 2003.

Tiilikainen Petter, "SIP (RFC 2543) An Implementation for Marratech Pro" Marratech, 2000.

ATutor homepage http://www.atutor.ca. ATutor Learning Content Management System. 2008

Rosenberg,dkk.2002.RFC3261 SIP (Session Initiation Protocol). http://www.ietf.org/rfc/rfc3261.txt diakses terakhir pada 9 Juli 2011. 
Unuth, Nadeem. Quality of Service - QoS and

VoIP.http://voip.about.com/od/voipbasics/a/qos.htm [diakses pada $10 \mathrm{Juli}$ 2011].

Anonim.2007.Understanding the Flex Application startup event order.

http://www.wietseveenstra.nl/blog/2007/02/understanding-the-flex-

application-startup- event-order/ [diakses pada 12 Mei 2011].

jsh Jurnal Sosial Humaniora, Vol 4 No.2, November 2011 